\title{
Nanostructural Surfaces with Different Elastic Moduli Regulate the Immune Response by Stretching Macrophages
}

Lan Chen ${ }^{a, b}$, Donghui Wang ${ }^{a}$, Feng Peng ${ }^{a, b}$, Jiajun Qiu ${ }^{a, b}$, Liping Ouyang ${ }^{a, b}$, Yuqin Qiao $^{a}$, Xuanyong Liu ${ }^{a, b, *}$

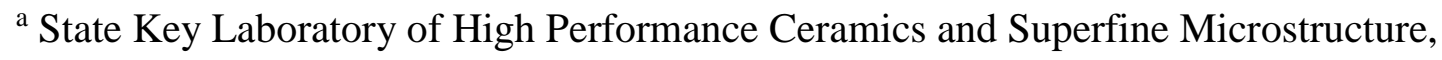
Shanghai Institute of Ceramics, Chinese Academy of Sciences, Shanghai 200050, China

${ }^{\mathrm{b}}$ Center of Materials Science and Optoelectronics Engineering, University of Chinese Academy of Sciences, Beijing 100049, China

*Corresponding Authors:

Prof. Xuanyong Liu: E-mail: xyliu@mail.sic.ac.cn; Tel.: +86 21 52412409; Fax: +86 2152412409. 


\section{Supplementary Data}

\section{Materials characterization}

From SEM images (Figures S1-S2), it is found that there are many ridge-like structures on Ti surface. After hydrothermal treatment, uniform nanostructures with different sizes are observed. As shown in Tables S1-S3, the measured length (b) and height (h) of nanoleaf on the NL sample are 102.4 \pm 8.1 and $305.4 \pm 12.9 \mathrm{~nm}$, those of nanosponge on the NS sample are $29.0 \pm 0.9$ and $474.0 \pm 25.3 \mathrm{~nm}$, and for the NW sample, these values are $38.0 \pm 1.6$ and $3.5 \pm 0.2 \mu \mathrm{m}$, the length and height of the NL samples are the smallest, while those of the NW sample are the largest (Figures S1-S2).

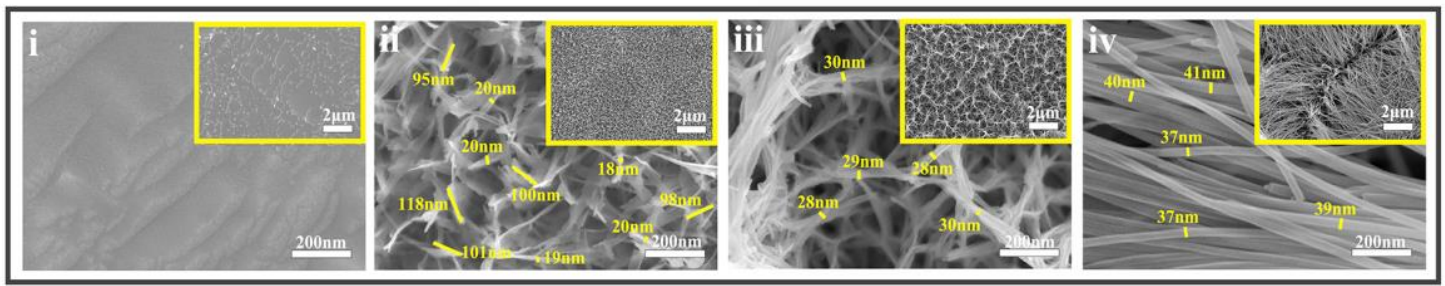

Figure S1. SEM images of surface morphology and geometry size of nanostructures on the various samples (i presents Ti; ii presents NL; iii presents NS; iv presents NW).

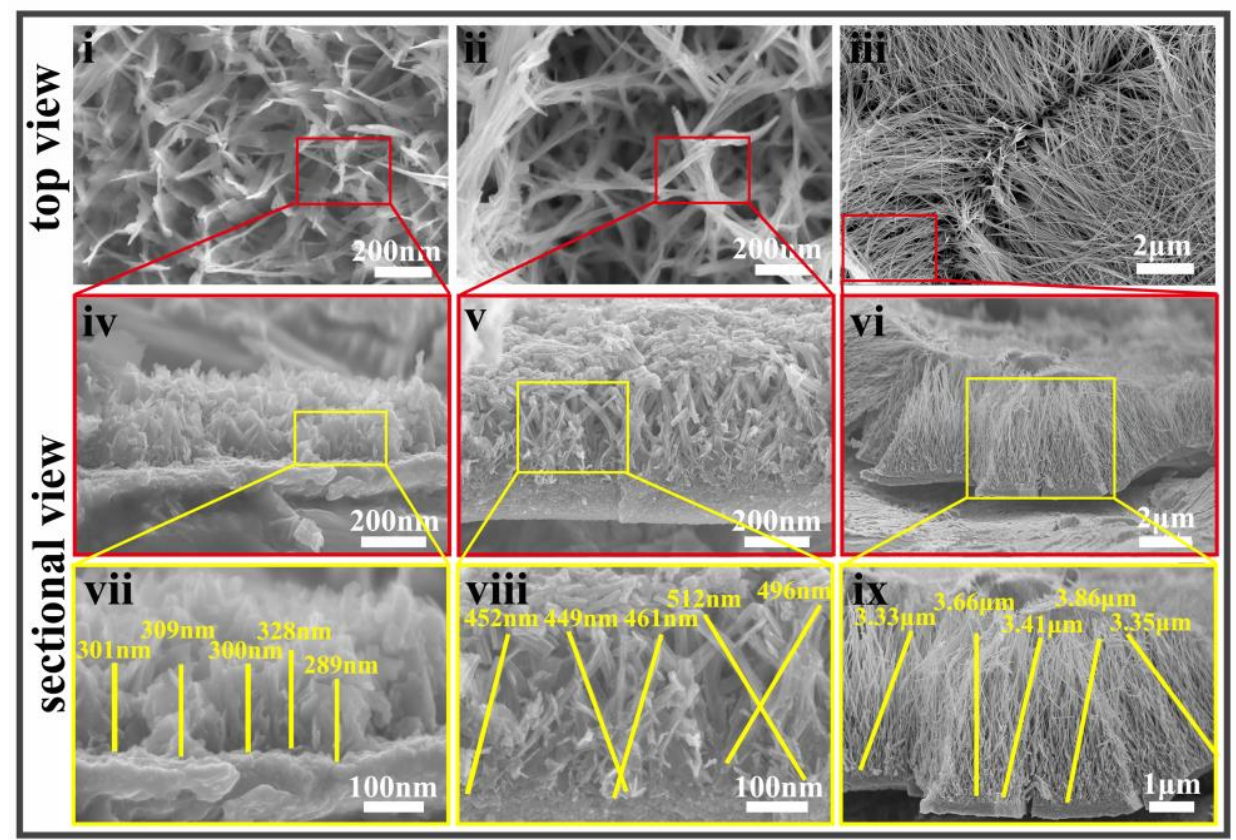

Figure S2. SEM images of top and cross section morphology and geometry size of nanostructures on the various samples (i, iv, and vii present NL; ii, v and viii present NS; iii, vi, and ix present NW). 
Table S1. Length of nanostructures on the various samples

\begin{tabular}{cccccccc}
\hline $\begin{array}{c}\text { Sample } \\
\text { name }\end{array}$ & & \multicolumn{5}{c}{ Length (nm) } \\
\hline NL & 95.0 & 118.0 & 100.0 & 98.0 & 101.0 & 102.4 & 8.1 \\
NS & 28.0 & 29.0 & 30.0 & 30.0 & 28.0 & 29.0 & 0.9 \\
NW & 40.0 & 41.0 & 39.0 & 37.0 & 37.0 & 38.8 & 1.6 \\
\hline
\end{tabular}

Table S2. Width of nanostructures on the various samples

\begin{tabular}{cccccccc}
\hline $\begin{array}{c}\text { Sample } \\
\text { name }\end{array}$ & & \multicolumn{5}{c}{ Width (nm) } \\
\hline NL & 20.0 & 20.0 & 19.0 & 18.0 & 20.0 & 19.4 & 0.8 \\
NS & 28.0 & 29.0 & 30.0 & 30.0 & 28.0 & 29.0 & 0.9 \\
NW & 40.0 & 41.0 & 39.0 & 37.0 & 37.0 & 38.8 & 1.6 \\
\hline
\end{tabular}

Table S3. Height of nanostructures on the various samples

\begin{tabular}{cccccccc}
\hline $\begin{array}{c}\text { Sample } \\
\text { name }\end{array}$ & & \multicolumn{5}{c}{ Height (nm) } \\
\hline NL & 301.0 & 309.0 & 300.0 & 328.0 & 289.0 & 305.4 & 12.9 \\
NS & 452.0 & 449.0 & 461.0 & 512.0 & 496.0 & 474.0 & 25.3 \\
NW & 3330.0 & 3660.0 & 3410.0 & 3860.0 & 3350.0 & 3522.0 & 206.0 \\
\hline
\end{tabular}

\section{Density of nanobundles on the various samples}

Based on the uniform distribution of the nanostructure on the sample surface, we randomly selected five areas under the low-magnification field of view, and calculated the density of the nanobundles in these five areas by ImageJ software to get the mean and standard deviation of the density of the nanobundles. As shown in Figure S3 and Table S4, the densities of nanobundles on the NL, NS, and NW samples are significantly different, which are $27.3 \pm 1.7,5.9 \pm 0.8$, and $0.0077 \pm 0.0021 \mu \mathrm{m}^{-2}$, respectively. 

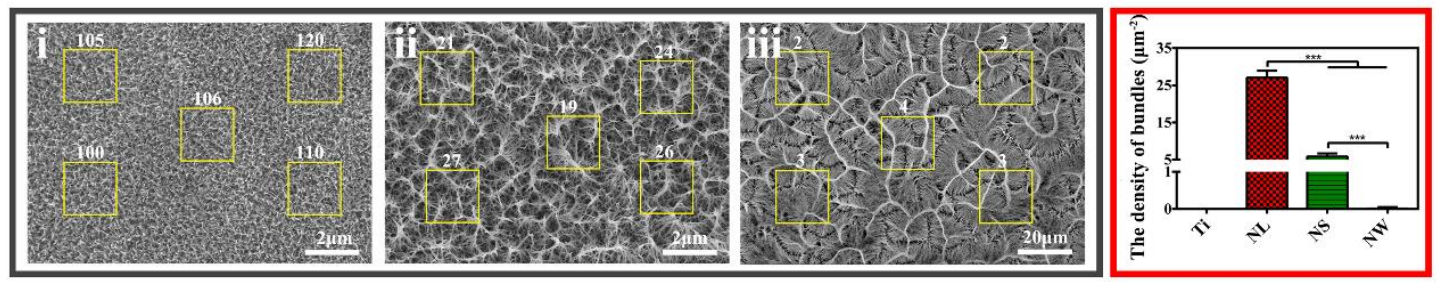

Figure S3. Density of nanobundles on the various samples (i presents NL; ii presents NS; iii presents NW).

Table S4. Density of nanobundles on the various samples

\begin{tabular}{cccccccc}
\hline $\begin{array}{l}\text { Sample } \\
\text { name }\end{array}$ & & & & & & \\
& & & & & Average & $\begin{array}{c}\text { Standard } \\
\text { deviation }\end{array}$ \\
\hline NL & 25.0 & 26.5 & 30.0 & 27.5 & 26.1 & 27.1 & 1.7 \\
$\mathrm{NS}$ & 5.3 & 6.8 & 4.7 & 6.0 & 6.5 & 5.9 & 0.8 \\
$\mathrm{NW}$ & $5.5 \times 10^{-3}$ & $5.5 \times 10^{-3}$ & $11.1 \times 10^{-3}$ & $8.3 \times 10^{-3}$ & $8.3 \times 10^{-3}$ & $7.7 \times 10^{-3}$ & $2.1 \times 10^{-3}$ \\
\hline
\end{tabular}

Table S5. Elements of the different sample surfaces

\begin{tabular}{cccc}
\hline Sample name & C 1s (\%) & O 1s (\%) & Ti 2p3 (\%) \\
\hline NL & 41.95 & 41.58 & 15.28 \\
NS & 39.32 & 43.61 & 16.16 \\
NW & 12.96 & 60.58 & 25.12 \\
\hline
\end{tabular}

\section{Elastic modulus analysis}

A fixed load $P$ acts on the tip of the nanostructure samples during testing, and the elastic modulus $E$ could be calculated by the following Equation S1,

$\mathrm{E}^{\prime}=\frac{\sigma}{\varepsilon}=\frac{\Delta P / n \times d \times h}{\Delta L / L_{0}}=\frac{L_{0} \times \Delta P}{d \times h \times \Delta L \times n}$

where $E^{\prime}$ is the elastic modulus of the $\mathrm{TiO}_{2}$ nanostructures, $\Delta P$ is the load increment, $\Delta L$ is the deformation incremental corresponding to $\Delta P, L_{0}$ is the gauge distance, $d$ and $h$ are the diameter and height of the $\mathrm{TiO}_{2}$ testing samples, respectively, $n$ is the number of nanostructures below the probe. 
Using Euler-Bernoulli's beam theory, we considered a force $P$ (load) acting on the tip of a nanostructure to the substratum. The beam theory predicts a deflection of the tip $\Delta L$ as

$\Delta \mathrm{L}=\frac{P / n \times h^{3}}{3 E I}$

where $I$ is the area moment, $E$ is the intrinsic elastic modulus of $\mathrm{TiO}_{2}$.

The moment of inertia of the rectangular section on the $\mathrm{X}$-axis is calculated by the following Equation S3.

$I_{X}=\frac{a d^{3}}{12}$

Where $a$ and $b$ are the length and width of the $\mathrm{TiO}_{2}$ nanostructures, respectively.

The tested elastic modulus of $\mathrm{TiO}_{2}$ nanostructures $\left(E^{\prime}\right)$ and the intrinsic elastic modulus of $\mathrm{TiO}_{2}\left(\mathrm{E}_{\mathrm{TiO} 2}\right)$ exists the following relation:

$E^{\prime}=\frac{L_{0}}{4 b_{\mathrm{TiO}_{2}} h_{\mathrm{TiO}_{2}}} \times a \times n \times\left(\frac{d}{h}\right)^{3} \times E_{\mathrm{TiO}_{2}}=A \times n \times\left(\frac{d}{h}\right)^{3} \times E_{\mathrm{TiO}_{2}}$

where $A^{\prime}$ is a parameter related to testing conditions and the basic properties of samples.

\section{In vitro experiments}

AlarmBlue $^{\mathrm{TM}}$ assay is applied to investigate the cell proliferation and the results are shown in Figure S4. No significant difference of cell proliferation is observed between $\mathrm{Ti}$ and nanostructure samples (Figure $\mathrm{S} 4 \mathrm{a}$ and $\mathrm{b}$ ). The images of live-dead stained cells shows that there is no difference in the number of live/dead cells on the nanostructures with different elastic moduli, which is consistent with the alarmBlue $\mathrm{e}^{\mathrm{TM}}$ test (Figure S4c). 

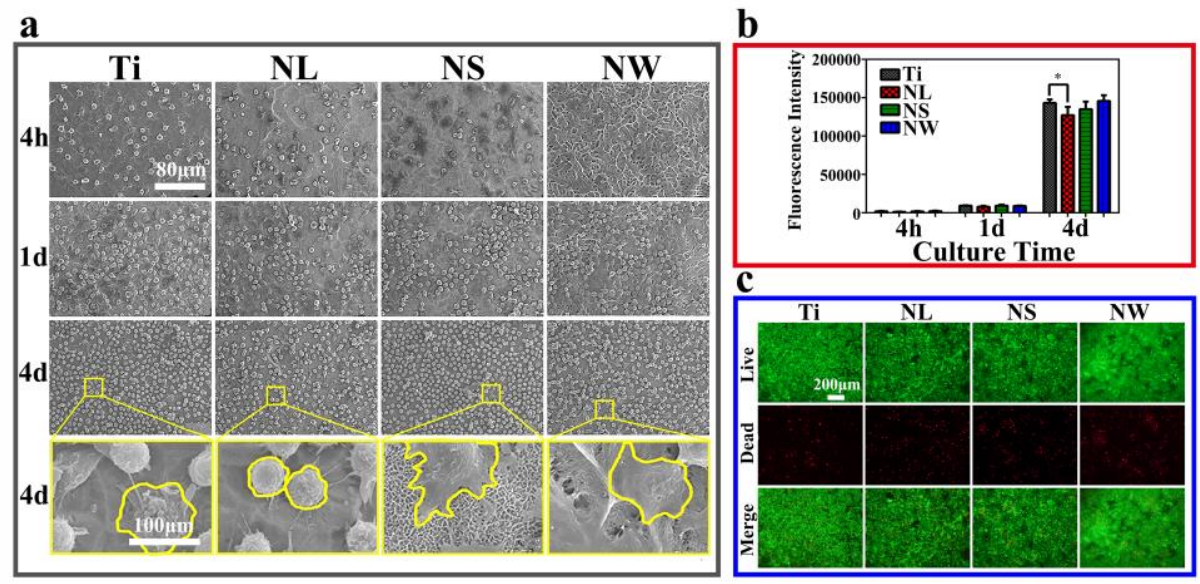

Figure S4. (a) SEM morphology of macrophages on the various samples after cultured for 4 hours, 1 and 4 days. (b) Reduction percentage of alamarBlue ${ }^{\mathrm{TM}}$ for macrophages cultured for various periods of time on the various surfaces. (c) CLSM images of the live-dead stained macrophages after incubation for 4 days on the various samples.

\section{Cell attachment area}

The average macrophage spreading areas on samples are $73.7 \pm 9.9,48.4 \pm 5.5$, $100.4 \pm 7.6$, and $162.9 \pm 12.2 \mu \mathrm{m}^{2}$, repectively, indicating that the area on the NW sample is about 3 times and 1.6 times higher than that on the NL and NS sample, respectively, and the cell spreading area on the NL sample is the lowest among four groups, the quantitative data and the graphic representations are shown in Figure S5 and Table S6.

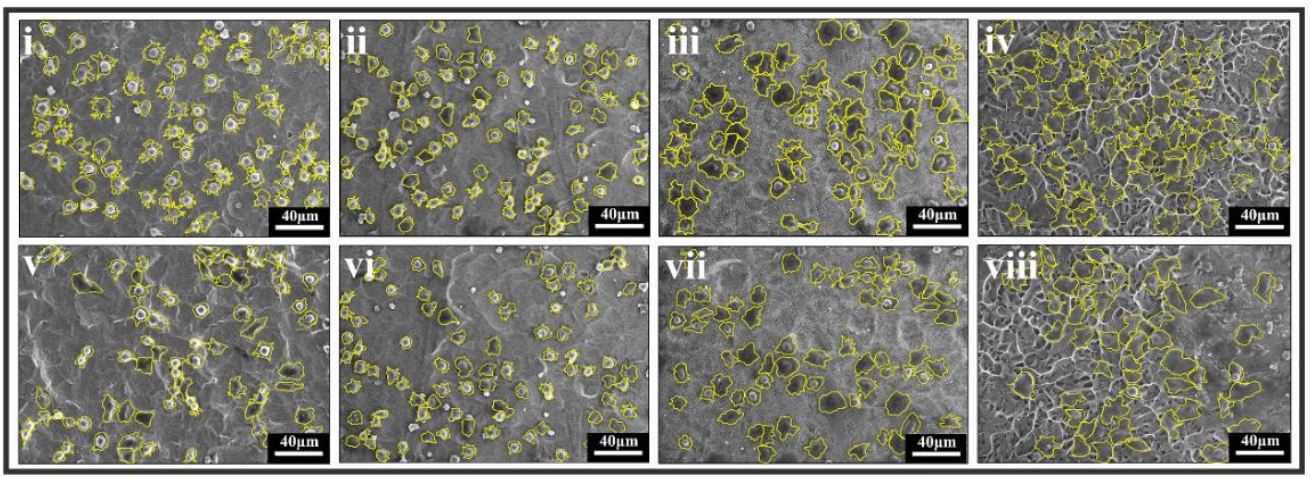

Figure S5. Two randomly selected low-magnification visual fields (500 times magnification by SEM) show the cell attachment area of macrophages on the samples at 4 hours. (i and v present Ti; ii and vi present NL; iii and vii present NS; iv and viii present NW). 
Table S6. Quantitative data of the cell attachment area of macrophages on the samples at 4 hours analyzed by ImageJ software

\begin{tabular}{cccc}
\hline $\begin{array}{c}\text { Sample } \\
\text { name }\end{array}$ & Cell & \multicolumn{2}{c}{ Cell attachment area $\left(\mu \mathrm{m}^{2}\right)$} \\
number & Average & Standard deviation \\
\hline $\mathrm{Ti}$ & 142 & 73.7 & 9.9 \\
$\mathrm{NL}$ & 168 & 48.4 & 5.5 \\
$\mathrm{NS}$ & 145 & 100.4 & 7.6 \\
$\mathrm{NW}$ & 139 & 162.9 & 12.2 \\
\hline
\end{tabular}

\section{Force analysis}

The effect of cell adhesion on the surface of nanostructure samples can be simplified as a cantilever beam under the fixed load as shown in Figure S6.

The deflection of cantilever beam under the fixed load $P / n$ is calculated by the following Equation S5.

$\mathrm{y}=-\frac{P / n \times \cos \theta \times x^{2}}{E I}(3 h-x)$

The maximum deflection of the Z-axis is calculated by the following Equation S6.

$y_{\max }=-\frac{P / n \times \cos \theta \times h^{3}}{3 E^{\prime} I}$

In conclusion, the maximum deflection of the cantilever beam with rectangular section under the fixed load is calculated by the following Equation S7.

$y_{\max }=-\frac{4 \times P / n^{\times} \cos \theta \times h^{3}}{E^{\prime} a b^{3}}$

The relation between the force and the maximum horizontal displacement is

$\mathrm{P}=\frac{a}{4 \sin \theta \cos \theta} \times n \times\left(\frac{\mathrm{d}}{h}\right)^{3} \times E^{\prime} \times \delta=A^{\prime} \times n \times\left(\frac{\mathrm{d}}{h}\right)^{3} \times E^{\prime} \times \delta$

where $A^{\prime}$ is a parameter related to testing conditions and the basic properties of samples. 


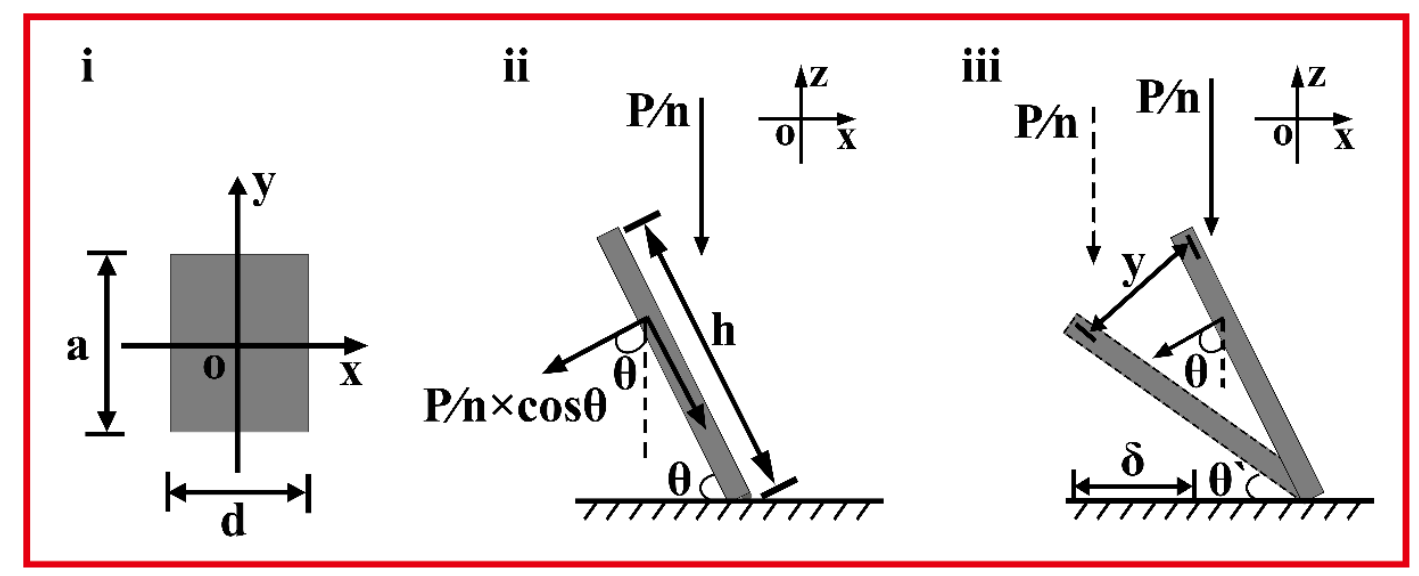

Figure S6. (i) The moment of inertia of the rectangular section, a and d are the width and diameter of the section. (ii, iii) The torsion of the cantilever beam under the external force, $P$ is the external force, $h$ is the length of the nanostructure, $\theta$ is the angle between the cantilever beam and the substrate, $\delta$ is the horizontal displacement of the tip, $n$ is the number of nanostructures below the probe.

\section{Distance between two tips of nanobundles on the samples}

The distance between two tips of nanobundles on the samples are $27.05 \pm 1.68$, $5.85 \pm 0.75,0.0077 \pm 0.0021 \mu \mathrm{m}$, respectively, this reveals that the spaces between the adjacent bundles are the smallest on the NL sample, those on the NS sample increase, and the spaces between two nanobundles on the NW sample is the largest (Figure S7 and Table S7).
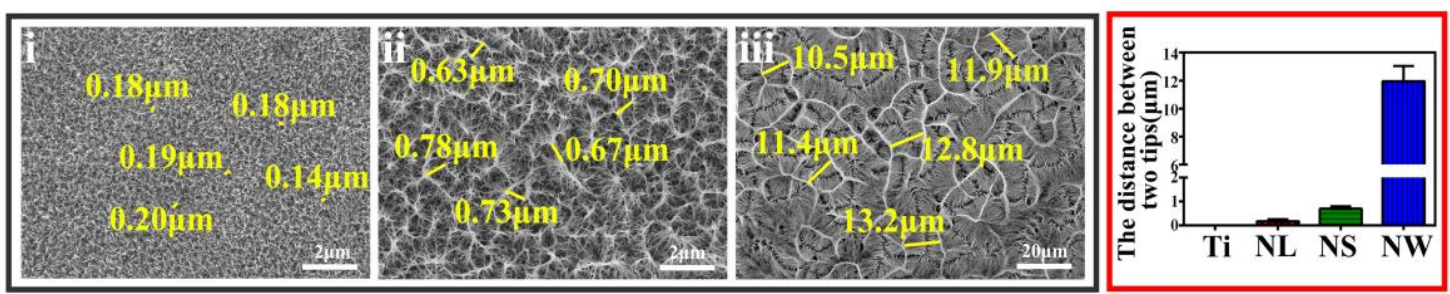

Figure S7. Distance between two tips of nanobundles on the various samples (i presents

NL; ii presents NS; iii presents NW). 
Table S7. Distance between two tips of nanobundles on the various samples

\begin{tabular}{cccccccc}
\hline $\begin{array}{c}\text { Sample } \\
\text { name }\end{array}$ & \multicolumn{4}{c}{ The distance between two tips of nanobundles $(\mu \mathrm{m})$} \\
\hline NL & 0.19 & 0.20 & 0.18 & 0.18 & 0.14 & 0.18 & 0.02 \\
NS & 0.67 & 0.73 & 0.63 & 0.70 & 0.76 & 0.70 & 0.05 \\
NW & 12.80 & 10.50 & 13.20 & 11.40 & 11.90 & 11.96 & 0.97 \\
\hline
\end{tabular}

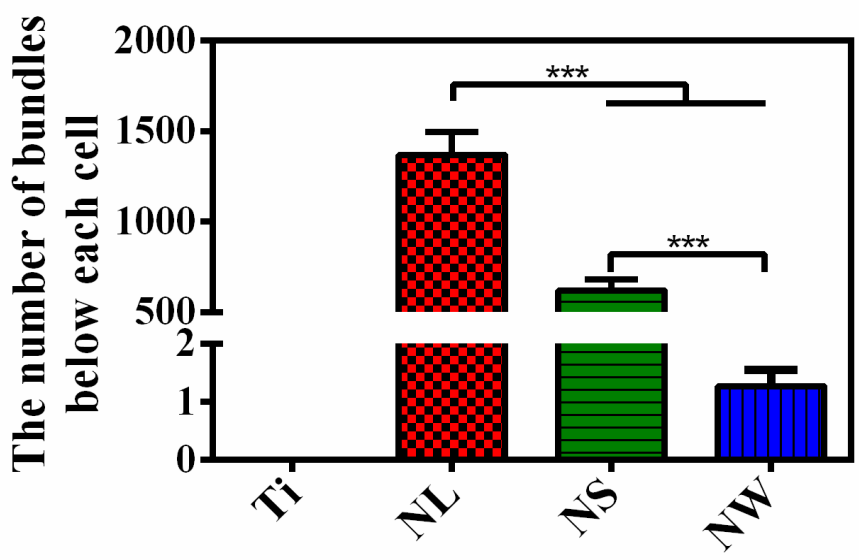

Figure S8. Number of nanobundles below each macrophage on the various samples at 4 hours.

Table S8. M2/M1 ratio of macrophages on the various samples

\begin{tabular}{cc}
\hline Sample name & The M2/M1 ratio of macrophages \\
\hline Ti & $0.1 \% / 15.1 \%=0.00662$ \\
NL & $0.9 \% / 64.5 \%=0.01395$ \\
NS & $0.4 \% / 83.8 \%=0.00477$ \\
NW & $0.4 \% / 66.3 \%=0.00603$ \\
\hline
\end{tabular}

\section{Immunofluorescence staining}

After incubation for 4 hours, a small number of macrophages were adhered to the surface of the samples, and the green fluorescence intensity of cells cultured on all the samples is strong. One day later, the red fluorescence intensity of macrophages on the 
NL sample was the strongest among all the samples. After incubation for 4 days, a large number of macrophages were growing on the sample surfaces, the red fluorescence intensity of macrophages on the NL sample was the strongest among all the samples (Figure S9).

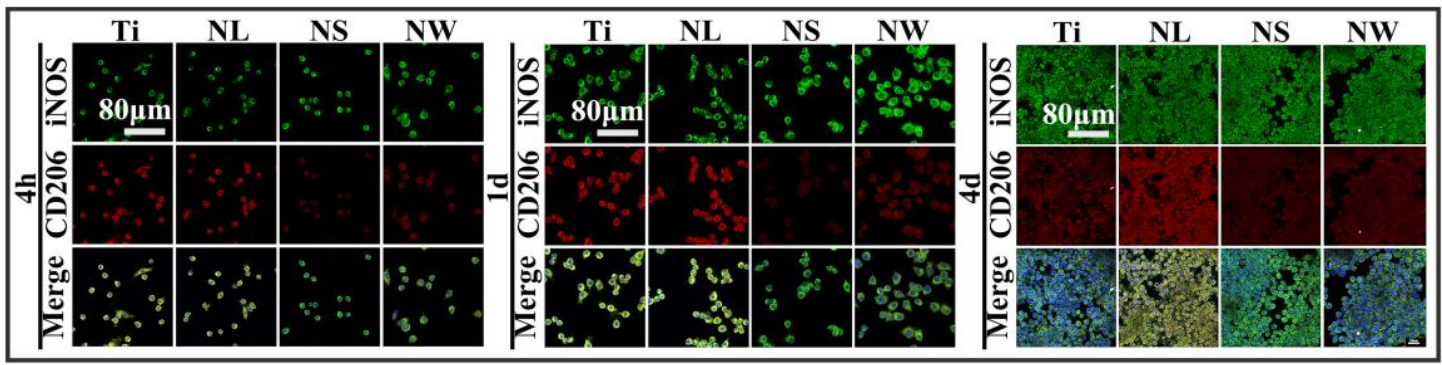

Figure S9. Immunofluorescence staining images for iNOS (green; M1 macrophages) and CD206 (red; M2 macrophages) of macrophages on the various samples.

\section{ROS generation}

Figure S10 shows the secretion of ROS by macrophages on nanostructures with different elastic moduli after cultured for 4 days. The amounts of ROS released by macrophages on the NS and NW samples are significantly higher than those released by cells on the Ti and NL samples. With increasing secretion of ROS, macrophages are more likely to convert into giant cell, release more inflammatory cytokines, enhance their phagocytosis and accelerate the corrosion of materials ${ }^{1,2}$.

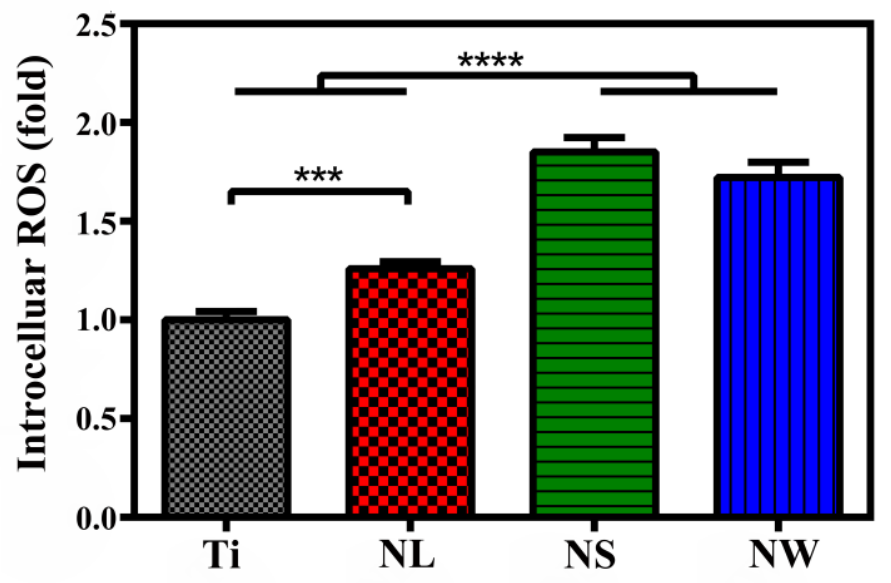

Figure S10. Intracellular ROS level of macrophages after cultured for 4 days on the various samples. 


\section{Materials and methods}

1. Materials

Titanium plates were machined into different dimensions. The samples with the dimensions of $20 \mathrm{~mm} \times 10 \mathrm{~mm} \times 1 \mathrm{~mm}$ were used to measure the surface zeta potential, and the samples with the dimensions of $20 \mathrm{~mm} \times 20 \mathrm{~mm} \times 1 \mathrm{~mm}$ were used in the flow cytometry and the real-time polymerase chain reaction (RT-PCR) tests. The other test samples were in the dimensions of $10 \mathrm{~mm} \times 10 \mathrm{~mm} \times 1 \mathrm{~mm}$. All the samples were pretreated with $\mathrm{HF}$ and $\mathrm{HNO}_{3}$ mixed aqueous solution to get rid of the oxide layers and acquire homogenous surfaces, then samples were ultrasonically cleaned in the absolute ethyl alcohol and ultrapure water ${ }^{3}$. Afterwards, the samples underwent hydrothermal treatment and the reaction conditions were shown in Table S9. The samples were then rinsed with ultrapure water gently and dried at room temperature, followed by being immersed in $0.1 \mathrm{M}$ hydrochloric acid $(\mathrm{HCl})$ solution for 2 hours, then rinsed with plenty of ultrapure water and dried at room temperature. ${ }^{4,5}$ Finally, the samples were heat treated in muffle furnace. ${ }^{6}$ According to the morphology of samples under SEM test, the samples were named as Ti, NL, NS, and NW.

Table S9. Concentration of $\mathrm{NaOH}$ and reaction time used in the treatment of different groups of samples

\begin{tabular}{cccc}
\hline $\begin{array}{c}\text { Sample } \\
\text { name }\end{array}$ & $\begin{array}{c}\text { Concentration of } \\
\mathrm{NaOH}\end{array}$ & $\begin{array}{c}\text { Reaction } \\
\text { temperature }\end{array}$ & $\begin{array}{c}\text { Reaction } \\
\text { time }\end{array}$ \\
\hline $\mathrm{Ti}$ & 0 & 0 & 0 \\
$\mathrm{NL}$ & $1 \mathrm{M}$ & $120^{\circ} \mathrm{C}$ & $8 \mathrm{~h}$ \\
$\mathrm{NS}$ & $5 \mathrm{M}$ & $120^{\circ} \mathrm{C}$ & $8 \mathrm{~h}$ \\
$\mathrm{NW}$ & $1 \mathrm{M}$ & $240^{\circ} \mathrm{C}$ & $4 \mathrm{~h}$ \\
\hline
\end{tabular}

2. Characterizations

2.1. Surface structure and chemical characterization

Field-emission scanning electron microscopy (FE-SEM, Hitachi SU8220, Japan) and atomic force microscope (AFM; Bruker Multimode 8 system, USA) were used to examine the surface topography and the parameters of sample surface roughness, 
including the mean roughness $(\mathrm{Ra})$ and the root-mean-square height $\mathrm{Z}$ data $(\mathrm{Rq})$, which were analyzed by NanoScope Analysis software. X-ray diffraction (XRD; D8 advance, Bruker, Germany) patterns were acquired with a $\mathrm{Cu} \mathrm{K \alpha}$ radiation $(\lambda=1.5411 \AA)$. X-ray photoelectron spectroscopy (XPS; PHI 5802, Physical Electronics Inc., Eden Prairie, MN, USA) was applied to analyze the chemical compositions and chemical states of the samples.

\subsection{Mechanics performance testing}

Nano indenter (G200, Agilent Technologies, USA) was carried out to measure the surface elastic modulus of samples within 100-500 nm.

\subsection{Contact angle analysis}

Contact angle measurements (Automatic Contact Angle Meter Model SL200B, Solon, China) were used to evaluate the surface wettability of samples. At room temperature, a $2 \mu \mathrm{L}$ deionized water droplet was dropped onto the sample surface and pictures were taken by a camera after stabilization. Four samples of each group were tested.

\section{In vitro studies}

\subsection{Macrophage culture}

The mouse mononuclear macrophage leukemia cells (RAW264.7; cells were kindly provided by Stem Cell Bank, Chinese Academy of Sciences, Shanghai, China) were seeded on cell culture plate (Thermo Fisher Scientific Inc., USA) and cultured in DMEM medium (high glucose; Gibco, USA) with 15\% heat-inactivated fetal bovine serum (FBS; Gibco, USA) and 1\% penicillin/streptomycin (Antibiotic-Antimycotic; Gibco, USA) in a humidified atmosphere of $5 \% \mathrm{CO}_{2}$ at $37^{\circ} \mathrm{C}$. The cells were passaged at a ratio of 1:3 every four days. All the samples were sterilized by $75 \%$ ethanol before the experiment.

\subsection{Cell proliferation and viability}

The cell proliferation and viability was measured by using the alamarBlue $\mathrm{T}^{\mathrm{TM}}$ (Thermo Fisher Scientific Inc., USA) assay. The cells with a density of $1 \times 10^{5}$ cells per well were seeded on the samples (three replicates) on 24-well plates for 4 hours, 1 and 4 days. For each incubation period, the samples were rinsed with $0.6 \mathrm{~mL}$ phosphate 
buffered saline (PBS) twice, then $0.5 \mathrm{~mL}$ fresh medium with $10 \%$ alamarBlue ${ }^{\mathrm{TM}}$ was added and cultured for another two hours. Afterwards, $0.1 \mathrm{~mL}$ medium were transferred into a black 96-well plate to detect an excitation wavelength at $560 \mathrm{~nm}$ and an emission wavelength at $590 \mathrm{~nm}$.

\subsection{Intracellular reactive oxygen radical (ROS) detection}

The reactive oxygen species (ROS) Assay Kit was used to investigate the intracellular ROS levels of the cells. 2', 7'-Dichloro-dihydrofluorescein diacetate (DCFH-DA) reacts with ROS and produces fluorescent 2', 7'-dichlorofluorescein (DCF). $1 \times 10^{5}$ cells were seeded on the samples (five replicates) on 24-well plates for 4 days. The cells on every group samples were collected by using $0.05 \%$ tyrisin (HyClone, USA), then DCFH-DA solution (Sigma-Aldrich, USA) was added and the collected cells were cultured for 30 minutes at $37^{\circ} \mathrm{C}$. Next, the cells were stained by 4 , 6-diamidino-2-phenylindole (DAPI; Sigma, USA), centrifuged at $1000 \mathrm{rpm}$ for 5 minutes and resuspended in PBS. An enzyme-labeling instrument (BioTek Cytation 5, USA) was used to detect the fluorescence intensity of DCF and DAPI. The intracellular ROS level was calculated as $\mathrm{F}_{\mathrm{DCF}} / \mathrm{F}_{\mathrm{DAPI}}, \mathrm{F}_{\mathrm{DCF}}$ represents the fluorescence intensity of DCF; FDAPI presents the fluorescence intensity of DAPI.

\subsection{Flow cytometry}

The expression levels of the cell-surface markers cluster of differentiation 206 (CD206) and C-C chemokine receptor type 7 (CCR7, also known as CD197) were determined by flow cytometry. $5 \times 10^{5}$ cells were seeded on the samples placed in 6well plates for 4 days. The cells were collected, centrifuged at $300 \mathrm{~g}$ for 5 minutes at $4{ }^{\circ} \mathrm{C}$, resuspended in stain buffer and then purified rat anti-mouse CD16/CD32 antibody (BD Pharmingen, USA) was added to block Fc-receptors for 10 minutes at room temperature. The detected cells were incubated with phycoerythrin (PE)-conjugated anti-mouse F4/80 antibody (BD Pharmingen, USA), Alexa Fluor 647-conjugeted antimouse CD206 antibody (BD Pharmingen, USA) and allophycocyanin (APC)-labeled anti-mouse CCR7 antibody (Cayman, USA) for 30 minutes at $4{ }^{\circ} \mathrm{C}$ in dark. The cells were rinsed twice with stain buffer and transferred to FACS tubes $(0.5 \mathrm{~mL}$ per tube) for test using BD LSRFortessa ${ }^{\mathrm{TM}}$ flow cytometer (BD, USA), 10,000 events per tube were 
analyzed. Results were processed by using BD FACSDiva software.

\subsection{Immunofluorescence Staining}

Macrophages were seeded on samples at a density of $1 \times 10^{5}$ cells per well for 4 hours, 1 and 4 days. At each time point, the cells were washed with PBS and fixed in $4 \%$ paraformaldehyde (PFA), permeabilized with $0.1 \%$ (v/v) Triton X-100, and $1 \mathrm{wt} \%$ BSA was added to block Fc-receptors. Then, the cells were incubated with primary antibodies against CD206 (Abcam, UK) and iNOS (Novus, USA) overnight at $4{ }^{\circ} \mathrm{C}$. Next, the cells were incubated with donkey anti-mouse IgG H\&L Alexa Fluor 594 (Abcam, UK) and donkey anti-rabbit IgG H\&L Alexa Fluor 488 (Invitrogen, Thermo Fisher Scientific Inc., USA) secondary antibodies for 2 hours. The nuclei were stained with DAPI for 10 minutes at room temperature in dark. The cells were observed with confocal laser scanning microscope (Leica TCS SP8, Germany).

\subsection{Enzyme-Linked immunosorbent assay (ELISA)}

Macrophages with a density of $1 \times 10^{5}$ cells per well were seeded on samples for 4 days, then, the cell culture medium was collected to measure the concentrations of interleukin-4 (IL-4; Anogen, Canada), interleukin-6 (IL-6; Anogen, Canada), interleukin-10 (IL-10; Raybiotech, USA) and tumor necrosis factor- $\alpha$ (TNF- $\alpha$; Anogen, Canada) by ELISA. The absorbance at $450 \mathrm{~nm}$ was determined using a microplate reader (Thermo Fisher Scientific Inc., USA). The concentrations of the above mentioned factors were calculated using standard curves.

3.7. Real-time polymerase chain reaction (RT-PCR) analysis

Cells were cultured on samples in DMEM medium with an initial density of $5 \times$ $10^{5}$ cells per well, and the total RNA was extracted using TRIzol ${ }^{\mathrm{TM}}$ reagent (Invitrogen, Thermo Fisher Scientific Inc., USA) after 4 days incubation. Complementary DNA (cDNA) was synthesized from $1 \mu \mathrm{g}$ total RNA using Transcriptor First Strand cDNA Synthesis Kit (Roche, Switzerland). RT-PCR was conducted on the LightCycler480 ${ }^{\circledR}$ system (Roche, Switzerland) using FastStart Universal SYBR Green I Master Mix (Roche, Switzerland). The relative expression levels of target genes were analyzed by the $2^{-\Delta \Delta C t}$ method and were normalized to that of the reference gene GAPDH. The primers for RT-PCR are listed in Table S10. All of the primers were purchased from 
BioTNT. RT-PCR experiments were performed at least two times each, and each sample was analyzed in triplicate. Relative expression was quantified using the comparative threshold method. ${ }^{7,8}$

\subsection{Western blot (WB) analysis}

Western blot analysis was performed to quantify NF-кB p65, phosphorylated-NFкB p65 (Ser536) and FAK protein levels. After cultured for 4 days, macrophages were lysed with ripa buffer (Beyotime, China), and protein levels were quantified using a bicinchoninic acid (BCA) kit (Thermo Fisher Scientific Inc., USA). Proteins were resolved by sodium dodecyl sulfate-polyacrylamide gel electrophoresis (SDS-PAGE), and transferred to nitrocellulose membranes. Membranes were blocked for 1 hour in Tris-buffered saline (TBS) -Tween 20 buffer containing 5\% (w/v) non-fat milk, then incubated with primary antibodies against NF- $\kappa$ B p65, phosphorylated-NF- $\kappa$ B p65 (Ser536), FAK and GAPDH (1:1,000; Cell Signaling Technology, USA) overnight at $4{ }^{\circ} \mathrm{C}$, after that, rinsed three times with TBS-Tween 20 and incubated with horseradish peroxidase-conjugated secondary antibodies for 1 hour at room temperature. After rinsing three times in TBS-Tween 20, protein bands were visualized using FluorChem ${ }^{\mathrm{TM}} \mathrm{M}$ system (Protein Simple, USA). The intensity of the protein bands was quantified by ImageJ software.

\section{In vivo studies}

\subsection{Mouse air-pouch model}

Six-week-old male pathogen-free C57BL/6 mice were maintained under specific pathogen-free conditions at the animal care facility in Shanghai Zhongshan hospital of Fudan University. The mouse air-pouch model was described previously ${ }^{9-11}$. Briefly, 4 $\mathrm{mL}$ of sterile air was injected subcutaneously into the lower dorsal area of mice to form an air pouch and a second injection of $3 \mathrm{~mL}$ of sterile air was performed four days later to reinforce the air pouch. Mice were anesthetized 48 hours later by intraperitoneal injection of $1 \%$ pentobarbital sodium solution ( $1 \mathrm{~mL}$ per $100 \mathrm{~g}$ body weight), and the fur over the air-pouch was shaved thoroughly. Under sterile conditions, a surgical incision was made, one sample was implanted in each mouse. 
The tissues were recovered from the mouse air-pouches 1 and 4 days after implantation. The air-pouch tissues were fixed in 4\% PFA for histological analysis and the samples were fixed in 4\% PFA for immunocytochemistry analysis after rinsed with PBS twice.

\subsection{Immunocytochemistry analysis of implanted samples}

$1 \mathrm{wt} \%$ BSA were added to block Fc-receptors, the samples were incubated with primary antibodies against CD206 (Abcam, UK) and iNOS (Novus, USA) at $4{ }^{\circ} \mathrm{C}$ for overnight and incubated with secondary antibodies for 2 hours. The samples were observed as described above.

\subsection{Histological analysis of air-pouch tissues}

The air-pouch tissues were embedded in paraffin wax, and sectioned to $4 \mu \mathrm{m}$. After dewaxing and dehydration, sections were stained with hematoxylin-eosin (HE) and Masson's trichrome. Stained sections were visualized by optical microscopy. Image J software was used to evaluate the thickness of fibrous capsule and the number of infiltrating cells in four random locations.

\section{Data analysis}

GraphPad Prism 6 was used for statistical analysis, ImageJ software was used to measure distance and areas. Quantitative data are expressed as mean \pm standard deviation. Statistically significant differences $(\mathrm{P})$ were analyzed by one-way analysis of variance and Tukey's multiple comparison tests. A value of $\mathrm{p}<0.05$ was considered statically significant and was represented by the symbol " "* ", a value of $p<0.01$ was represented by “***”, p $<0.001$ was “****”, and $\mathrm{p}<0.0001$ was “ “****». 
Table S10. Primers used for real-time PCR

\begin{tabular}{|c|c|c|}
\hline Gene (mouse) & $\begin{array}{c}\text { Primer sequences } \\
(\mathrm{F}, \text { forward; R, reverse; 5'-3') }\end{array}$ & Product size (bp) \\
\hline GAPDH & $\begin{array}{l}\text { F:GCT CAG GCC TCT GCG CCC T } \\
\text { R: CCT ACT CTC TTG AAT ACC }\end{array}$ & 115 \\
\hline CD86 & $\begin{array}{c}\text { F:TGC TCA TCA TTG TAT GTC A } \\
\text { R: CTG GAA AGG TCT GGA GAA TGC }\end{array}$ & 97 \\
\hline CD163 & $\begin{array}{l}\text { F:GAG TTA ATG CCA GTG AGG G } \\
\text { R: AGA TTG CCT CAT GAC TGC TC }\end{array}$ & 133 \\
\hline IL-4 & $\begin{array}{c}\text { F:CCA TGA ATG AGT CCA AGT CC } \\
\text { R: TAA CTT ATG AAT TTT TAA T }\end{array}$ & 60 \\
\hline IL-6 & $\begin{array}{l}\text { F:CCA AGA GGT AAA AGA TTT AC } \\
\text { R: ATT GAT AAT TTA AAT AAG TA }\end{array}$ & 161 \\
\hline IL-10 & $\begin{array}{c}\text { F:CCC TTT GCT ATG GTG TCC T } \\
\text { R: GTG GCC AGT TTG TTA TTT AT }\end{array}$ & 106 \\
\hline TNF- $\alpha$ & $\begin{array}{c}\text { F:GTT CCC AAA TGG CCT CCC } \\
\text { R: GTG CTC CTC ACC CAC ACC G }\end{array}$ & 103 \\
\hline Integrin $\alpha_{v}$ & $\begin{array}{c}\text { F:TCA TCT TGG CAG TTC TCG CAG } \\
\text { R: GTT CAC CAC CGT GGT GGT G }\end{array}$ & 100 \\
\hline Integrin $\beta_{3}$ & $\begin{array}{c}\text { F:GAC TGG GTT CTG GGT TCT G } \\
\text { R: AGA CTG TTT AGA TGA GGA AAC }\end{array}$ & 100 \\
\hline FAK & $\begin{array}{l}\text { F:AAG AAC AAT GAT GTG ATC GG } \\
\text { R: CCT TTG GGA GAT CTT CTC T }\end{array}$ & 88 \\
\hline PI3K & $\begin{array}{l}\text { F:TGT GGC TGA CGC AGA AAG G } \\
\text { R: AAG CAA AGG GCT CCT CTC CA }\end{array}$ & 110 \\
\hline PDK1 & $\begin{array}{l}\text { F:ACA GTA GGG AAA GGC TTA G } \\
\text { R: TCT CTT ATG TCA TCA GGT TT }\end{array}$ & 101 \\
\hline AKT & $\begin{array}{l}\text { F:CAG TTT GTT GCT GTG TCC CAT } \\
\text { R: CCC GCT GTC CGT CAC CCT G }\end{array}$ & 69 \\
\hline $\mathrm{IKK} \alpha$ & $\begin{array}{c}\text { F:GAA GTT CGG TTT AGT AGC CA } \\
\text { R: CAA TTA TAC AGC TGC GGA AAG T }\end{array}$ & 125 \\
\hline $\mathrm{NF}-\kappa \mathrm{B}$ & $\begin{array}{l}\text { F:TGA CAA GGT TCA GAA AGA T } \\
\text { R: CTG AAG GTG AAG GGC CCA }\end{array}$ & 124 \\
\hline ERK & $\begin{array}{l}\text { F:AAC CTC CTG CTG AAC ACC ACT } \\
\text { R: GAC TTT TAT GGA AGA AAA TA }\end{array}$ & 103 \\
\hline
\end{tabular}




\section{References}

(1) Cheung, E. C.; Lee, P.; Ceteci, F.; Nixon, C.; Blyth, K.; Sansom, O. J.; Vousden, K.

H. Genes Dev 2016, 30, (1), 52-63.

(2) Shi, J.; Sun, X.; Lin, Y.; Zou, X.; Li, Z.; Liao, Y.; Du, M.; Zhang, H. Biomaterials 2014, 35, (24), 6657-66.

(3) Qiu, J.; Geng, H.; Wang, D.; Qian, S.; Zhu, H.; Qiao, Y.; Qian, W.; Liu, X. ACS Appl Mater Interfaces 2017, 9, (14), 12253-12263.

(4) Ho, L. N.; Ishihara, T.; Ueshima, S.; Nishiguchi, H.; Takita, Y. J. Colloid Interface Sci. 2004, 272, (2), 399-403.

(5) He, M.; Feng, X.; Lu, X. H.; Ji, X. Y.; Liu, C.; Bao, N. Z.; Xie, J. W. J. Chem. Eng. Jpn. 2003, 36, (10), 1259-1262.

(6) Li, J.; Liu, X.; Qiao, Y.; Zhu, H.; Li, J.; Cui, T.; Ding, C. RSC Advances 2013, 3, (28), 11214.

(7) Jin, G.; Qin, H.; Cao, H.; Qiao, Y.; Zhao, Y.; Peng, X.; Zhang, X.; Liu, X.; Chu, P. K. Biomaterials 2015, 65, 22-31.

(8) Qiao, Y.; Zhang, W.; Tian, P.; Meng, F.; Zhu, H.; Jiang, X.; Liu, X.; Chu, P. K. Biomaterials 2014, 35, (25), 6882-97.

(9) Hui, W.; Zhao, C.; Bourgoin, S. G. Mediators of Inflammation 2015, 2015, 1-9.

(10) Vasconcelos, D. P.; Costa, M.; Amaral, I. F.; Barbosa, M. A.; Aguas, A. P.; Barbosa, J. N. Biomaterials 2015, 53, 566-73.

(11) Yuan, X.; Cao, H.; Wang, J.; Tang, K.; Li, B.; Zhao, Y.; Cheng, M.; Qin, H.; Liu, X.; Zhang, X. Front Immunol 2017, 8, 1196. 